\title{
Examining the Value of Global Seasonal Reference Evapotranspiration Forecasts to Support FEWS NET's Food Insecurity Outlooks ${ }^{\mathscr{O}}$
}

\author{
ShraddhanAnd Shukla, ${ }^{\mathrm{a}}$ Daniel McEvoy, ${ }^{\mathrm{b}}$ Mike Hobbins, ${ }^{\mathrm{c}, \mathrm{d}}$ Greg Husak, ${ }^{\mathrm{a}}$ \\ Justin Huntington, ${ }^{\mathrm{b}}$ CHRIS Funk, ${ }^{\mathrm{e}, \mathrm{a}}$ Denis MACHARIA, ${ }^{\mathrm{f}}$ AND JAMEs VERDin ${ }^{\mathrm{e}}$ \\ ${ }^{a}$ University of California, Santa Barbara, Santa Barbara, California \\ ${ }^{\mathrm{b}}$ Desert Research Institute, Reno, Nevada \\ ${ }^{\mathrm{c}}$ Physical Sciences Division, NOAA/Earth System Research Laboratory, Boulder, Colorado \\ ${ }^{\mathrm{d}}$ Cooperative Institute for Research in Environmental Sciences, University of Colorado, Boulder, Colorado \\ ${ }^{\mathrm{e}}$ Earth Resources Observation and Science Center, U.S. Geological Survey, Sioux Falls, South Dakota \\ ${ }^{\mathrm{f}}$ Regional Centre for Mapping of Resources for Development, Nairobi, Kenya
}

(Manuscript received 18 April 2017, in final form 16 August 2017)

\begin{abstract}
The Famine Early Warning Systems Network (FEWS NET) team provides food insecurity outlooks for several developing countries in Africa, central Asia, and Central America. This study describes development of a new global reference evapotranspiration $\left(\mathrm{ET}_{0}\right)$ seasonal reforecast and skill evaluation with a particular emphasis on the potential use of this dataset by FEWS NET to support food insecurity early warning. The $\mathrm{ET}_{0}$ reforecasts span the 1982-2009 period and are calculated following the American Society for Civil Engineers formulation of the Penman-Monteith method driven by seasonal climate forecasts of monthly mean temperature, humidity, wind speed, and solar radiation from the National Centers for Environmental Prediction CFSv2 model and the National Aeronautics and Space Administration GEOS-5 model. The skill evaluation, using deterministic and probabilistic scores, focuses on the December-February (DJF), March-May (MAM), June-August (JJA), and SeptemberNovember seasons. The results indicate that $\mathrm{ET}_{0}$ forecasts are a promising tool for early warning of drought and food insecurity. Globally, the regions where forecasts are most skillful (correlation $>0.35$ at leads of 2 months) include the western United States, northern parts of South America, parts of the Sahel region, and southern Africa. The FEWS NET regions where forecasts are most skillful (correlation $>0.35$ at lead 3) include northern sub-Saharan Africa (DJF; dry season), Central America (DJF; dry season), parts of East Africa (JJA; wet season), southern Africa (JJA; dry season), and central Asia (MAM; wet season). A case study over parts of East Africa for the JJA season shows that $\mathrm{ET}_{0}$ forecasts in combination with the precipitation forecasts would have provided early warning of recent severe drought events (e.g., in 2002, 2004, 2009) that contributed to substantial food insecurity in the region.
\end{abstract}

\section{Introduction}

The Famine Early Warning Systems Network (FEWS NET) is a leading provider of early warning and analysis on acute food insecurity (http://www.fews.net/about-us) to help government decision-makers and relief agencies plan for and respond to humanitarian crises in 36 of the most food-insecure countries, mainly located in Africa, Central America, and central Asia. Agroclimatologythe condition of climate and agriculture-is one of the

Supplemental information related to this paper is available at the Journals Online website: https://doi.org/10.1175/ JAMC-D-17-0104.s1.

Corresponding author: Shraddhanand Shukla, shrad@geog.ucsb.edu four primary dimensions of food insecurity assessments, along with livelihoods, markets and trade, and nutrition.

For agroclimatological monitoring, FEWS NET uses several datasets (http://earlywarning.usgs.gov/fews) from remotely sensed (Brown et al. 2007) to in situ (Velpuri et al. 2014) and modeling sources, such as Climate Hazards Group InfraRed Precipitation with Station (Funk et al. 2015), "eMODIS" (Jenkerson et al. 2010), and FEWS NET Land Data Assimilation System (McNally et al. 2017). For early warning, however, FEWS NET's primary focus has so far been on the precipitation forecasts for the upcoming season. Precipitation, as important as it is for agroclimatological conditions, only reflects one

Publisher's Note: This article was revised on 15 November 2017 to correct the order of affiliations for author Chris Funk. 
side of the crop water balance, the other one being actual evapotranspiration (AET - the flux of the moisture from the cropped surface to the atmosphere), which is also influenced by evaporative demand (the demand in the atmosphere for AET).

FEWS NET currently provides scenarios of crop-yield conditions that are based on the expected precipitation scenarios but only the climatological mean values of evaporative demand, which therefore do not account for evaporative demand's 1) interannual variability and 2) potential long-term changes due to global warming. To fill this gap, FEWS NET has recently invested in building reference evapotranspiration ( $\mathrm{ET}_{0}$; Allen et al. 2005) monitoring datasets and forecasts. This effort is timely in that recent studies have highlighted the value of $\mathrm{ET}_{0}$ for drought monitoring and forecasting. For example, the evaporative demand drought index (Hobbins et al. 2016; McEvoy et al. 2016a), which is based on $\mathrm{ET}_{0}$ and exploits the land-atmosphere interactions found between AET and $\mathrm{ET}_{0}$, has been shown to provide early warning of drought conditions. Moreover, McEvoy et al. (2016b) demonstrated the potential of seasonal forecasts of $\mathrm{ET}_{0}$ anomalies from the National Centers for Environmental Prediction (NCEP) Climate Forecast System, version 2 (CFSv2; Saha et al. 2014), in providing improved skill relative to precipitation for seasonal drought predictions across the United States (especially during the summer growing season in the central and northeastern United States).

This study provides a first skill evaluation of global seasonal $\mathrm{ET}_{0}$ forecasts for their potential use in food insecurity assessments by FEWS NET. The primary objectives of this study are 1) to develop $\mathrm{ET}_{0}$ reforecasts at a global scale, 2) to analyze their skill globally with particular emphasis on FEWS NET focus regions, and 3) to illustrate how $\mathrm{ET}_{0}$ forecasts can be used for drought early warning applications.

\section{Data and methods}

\section{a. Reference evapotranspiration (ET $)$ forecasts}

$\mathrm{ET}_{0}\left(\mathrm{~mm} \mathrm{day}^{-1}\right)$ forecasts are calculated following the American Society for Civil Engineers (ASCE) formulation of the Penman-Monteith method (Allen et al. 2005):

$$
\begin{aligned}
\mathrm{ET}_{0}= & \frac{\Delta}{\Delta+\gamma\left(1+C_{d} U_{2}\right)} \frac{R_{n}-G}{\lambda} \\
& +\frac{\gamma}{\Delta+\gamma\left(1+C_{d} U_{2}\right)} \frac{C_{n}}{T+273} U_{2}\left(e_{s}-e_{a}\right),
\end{aligned}
$$

where $R_{n}$ is net radiation ( $\mathrm{MJ} \mathrm{m}^{-2} \mathrm{day}^{-1}$ ), $G$ is ground heat flux $\left(\mathrm{MJ} \mathrm{m}^{-2} \mathrm{day}^{-1}\right), T$ is mean daily temperature $\left({ }^{\circ} \mathrm{C}\right), U_{2}$ is mean daily wind speed at $2 \mathrm{~m}\left(\mathrm{~m} \mathrm{~s}^{-1}\right), e_{s}$ is saturation vapor pressure $(\mathrm{kPa}), e_{a}$ is actual vapor pressure $(\mathrm{kPa}), \lambda$ is latent heat of vaporization $\left(\mathrm{MJ} \mathrm{kg}^{-1}\right)$, $\Delta$ is the slope of the saturation vapor pressure-temperature curve $\left(\mathrm{kPa}^{\circ} \mathrm{C}^{-1}\right)$ at $T, \gamma$ is the psychrometric constant, $C_{n}=$ 900 (grass reference), and $C_{d}$ is 0.34 (grass reference). The values of $\Delta, \gamma, e_{s}$, and $e_{a}$ are estimated using $T$, specific humidity, and mean elevation (used to estimate atmospheric pressure). The ensemble forecasts of monthly mean maximum temperature, minimum temperature, downward shortwave radiation, specific humidity, and wind speed are taken from two different forecast systems: 1) the NCEP CFSv2 (24-28 members) and 2) the National Aeronautics and Space Administration (NASA) Goddard Earth Observing System Model, version 5 (GEOS-5; Takacs et al. 1994; Molod et al. 2015; 11 members). These are the only two models contributing to the North American Multimodel Ensemble (NMME; Kirtman et al. 2014) system for which reforecasts of all four climate drivers needed to calculate $\mathrm{ET}_{0}$ are accessible. Monthly CFSv2 and GEOS-5 $\mathrm{ET}_{0}$ anomalies are calculated relative to the model reforecast monthly climatological means (1982-2009) from the corresponding initialization month and lead time, as in McEvoy et al. (2016b) and Kumar et al. (2014). The forecast skill has been calculated using the reforecast $\mathrm{ET}_{0}$ anomaly, which reduced any systematic bias with the benchmark $\mathrm{ET}_{0}$ dataset.

\section{b. Skill scores}

The benchmark $\mathrm{ET}_{0}$ dataset used for calculating skill of $\mathrm{ET}_{0}$ forecasts is also generated following ASCE's Penman-Monteith method but uses NASA's ModernEra Retrospective Analysis for Research and Applications, version 2 (MERRA-2), atmospheric forcings and is spatially downscaled using a finer-resolution climatological mean of the International Water Management Institute monthly global potential evapotranspiration dataset. The skill is evaluated using deterministic and probabilistic skill scores. The sections below describe briefly the methods used to calculate those skill scores; further details can be found in Shukla et al. (2017).

\section{1) DETERMINISTIC SKILL SCORE}

The correlation between the ensemble mean of the forecast anomalies and observed anomalies is calculated for 1982-2009 for each forecast period, lead time, and grid cell. The ensemble mean of the forecast anomalies is calculated by first converting each of the individual ensemble members into an anomaly (Kumar et al. 2014) and then calculating the mean of the anomalies. 

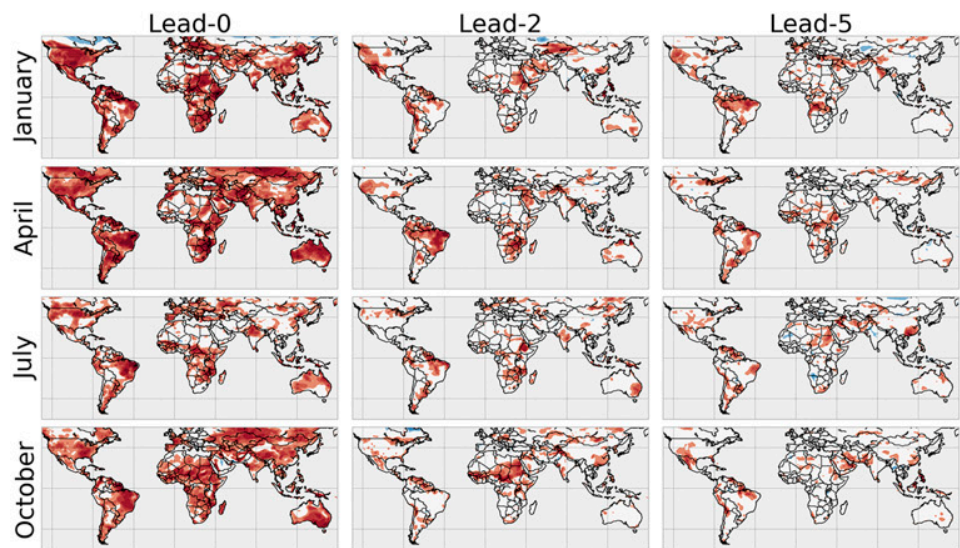

(a)

$\begin{array}{llllllllllll}-0.90 & -0.80 & -0.70 & -0.60 & -0.50 & -0.35 & 0.35 & 0.50 & 0.60 & 0.70 & 0.80 & 0.90\end{array}$

Correlation

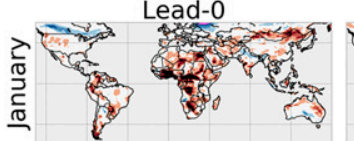

Lead-2
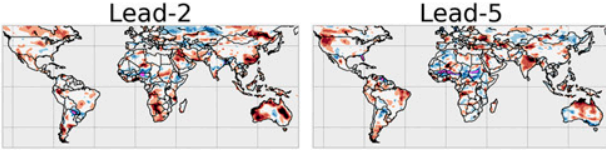

난
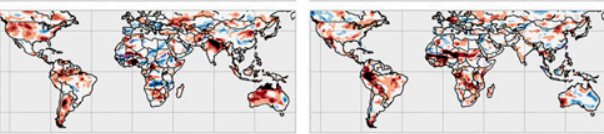

갈
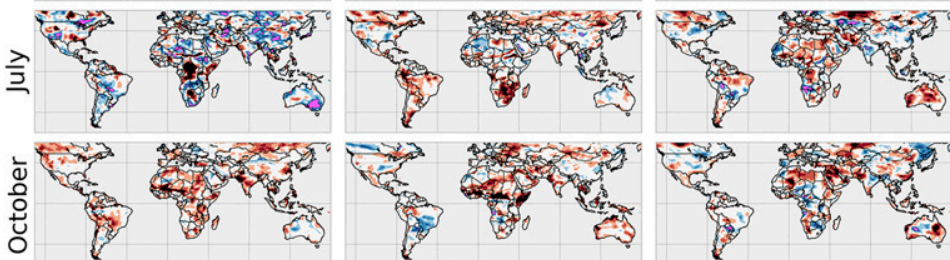

(b)
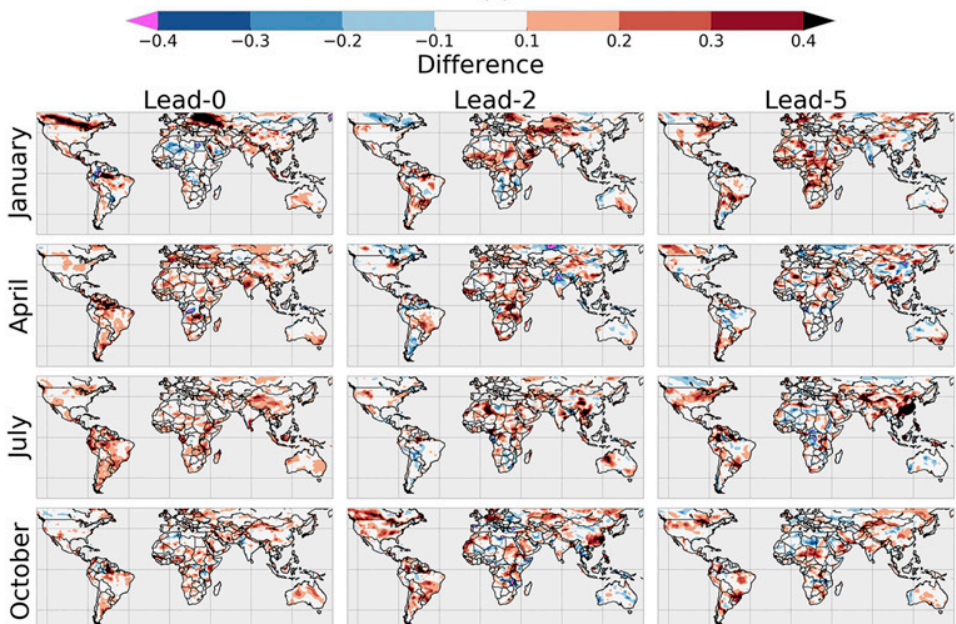

(c)

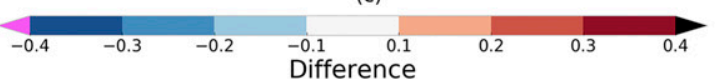

FIG. 1. (a) Deterministic skill (correlation) of 0-, 2-, and 5-month-lead multimodel ensemble mean $\mathrm{ET}_{0}$ forecasts initialized in January, April, July, and October. "Multimodel" refers to forecasts from both the CFSv2 and GEOS-5 models (total 35 members). The ensemble mean is the mean of the anomalies of the 35 members, where the anomaly for each member is calculated using its own climatological mean (for the given member and given lead time). Also shown is the difference between multimodel (CFSv2 and GEOS-5 combined) skill and (b) CFSv2 and (c) GEOS-5 0-, 2-, and 5-month-lead monthly $\mathrm{ET}_{0}$ forecasts initialized in January, April, July, and October. 
TABLE 1. List of the regions and seasons with $\mathrm{ET}_{0}$ forecast skill persisting up to 3 -month lead.

\begin{tabular}{lcc}
\hline \hline \multicolumn{1}{c}{ Region } & Season & Type of season \\
\hline Northern sub-Saharan Africa & DJF & Dry season \\
Central America & DJF & $\begin{array}{l}\text { Dry season } \\
\text { East Africa (mainly Ethiopia, }\end{array}$ \\
$\quad$ JJA & Wet season \\
$\begin{array}{l}\text { Sudan, and Uganda) } \\
\text { Central Asia }\end{array}$ & JJA & Dry season \\
& MAM & Wet season \\
\hline
\end{tabular}

\section{2) Probabilistic SKill SCORE}

The ranked probability skill score (RPSS) is calculated to evaluate the $\mathrm{ET}_{0}$ ensemble forecasts for tercile categories (upper, normal, and lower tercile) events. Terciles are commonly used in probabilistic forecasts by FEWS NET, and so evaluating forecasts on the basis of how well they can identify the correct tercile is an appropriate benchmark. The RPSS is found from

$$
\text { RPSS }=1-\frac{\text { RPS }_{\text {forecast }}}{\operatorname{RPS}_{\text {climatology }}} .
$$

The ranked probability score (RPS) is calculated as

$$
\mathrm{RPS}=\frac{1}{M-1} \sum_{m-1}^{M}\left(\sum_{k=1}^{m} F_{k}-\sum_{k=1}^{m} O_{k}\right)^{2},
$$

where $M$ is the number of forecast categories, $F_{k}$ is the predicted probability in forecast category $k$, and $O_{k}$ is an indicator $(0=$ no; $1=$ yes $)$ for the observation in category $k$. The RPSS measures how well a given ensemble forecast does relative to a reference forecast (e.g., a climatological forecast that assigns 33.33\% probability to each of the tercile categories) in forecasting the tercile category into which observations fell. It rewards a forecast for the number of ensemble members that fall within the observed category: the larger that number is, the higher is the RPSS. RPSS $>0$ is considered to be skillful, and an RPSS of 1 indicates a perfect forecast.

\section{3) Reliability}

The reliability of $\mathrm{ET}_{0}$ forecasts is calculated using reliability diagrams. A reliability diagram shows how often a given forecast probability of a given category (e.g., a particular tercile) is realized in observations; it can be applied directly to decision making. A perfectly reliable ensemble forecast system would have 1:1 association with the observed frequency.

\section{Evaluation of $\mathbf{E T}_{\mathbf{0}}$ forecasts}

\section{a. Skill evaluation globally}

Figure 1 shows globally the deterministic skill of the monthly multimodel $\mathrm{ET}_{0}$ forecasts initialized in January, April, July, and October at a lead time of 0,2 , and 5 months. Here, "lead 0" refers to a contemporaneous forecast (e.g., a forecast for January made in early January) and "lead 2" refers to a forecast for 2 months following the forecast initialization period (e.g., a forecast for March made in early January). The forecast skill in this format highlights that, across most of the globe, skill is generally the highest at lead 0 but decays rapidly afterward and that skill varies with lead time and season. For example, over the conterminous United States, the skill is highest for forecasts initialized in January. For some parts of the western United States skill persists through lead 5, whereas the skill at lead 0 for forecasts initialized in July is limited to parts of the northern, western, and central United States and dissipates after lead 0. The lead0 skill over the central United States is also reported by McEvoy et al. (2016b). Other skillful regions (correlation $>0.35$ at 2-month lead) include northern parts of South America, parts of the Sahel region, and southern Africa.

Figures $1 \mathrm{~b}$ and $1 \mathrm{c}$ show that, in general, the skill of multimodel forecasts is greater than the skill of any of the individual models. Several regions (e.g., eastern and southern Africa in Fig. 1b) show positive differences in Figs. $1 \mathrm{~b}$ and $1 \mathrm{c}$. This finding validates the use of both models in generating ensemble $\mathrm{ET}_{0}$ forecasts. As forecasts of the climate drivers become available from the other NMME models, they eventually will be added to this ensemble of $\mathrm{ET}_{0}$ forecasts, which potentially will further increase the skill.

\section{b. Skill evaluation over FEWS NET regions}

Next, the skill evaluation is conducted for FEWS NET focus regions: Africa, central Asia, and Central America. The seasons considered for this study are September-November (SON), December-February (DJF), March-May (MAM), and June-August (JJA). Figure S1 of the online supplemental information shows the fraction of annual precipitation received during each of those seasons in FEWS NET focus regions to identify climatologically wet or dry seasons in each of the regions, and Table 1 lists the dry and wet seasons for each region. From the perspective of FEWS NET, generally wet seasons are important for agricultural conditions and generally dry seasons are important for pasture conditions.

Figure 2 shows the deterministic skill score of $\mathrm{ET}_{0}$ forecasts for each of the focus regions and for each of the 


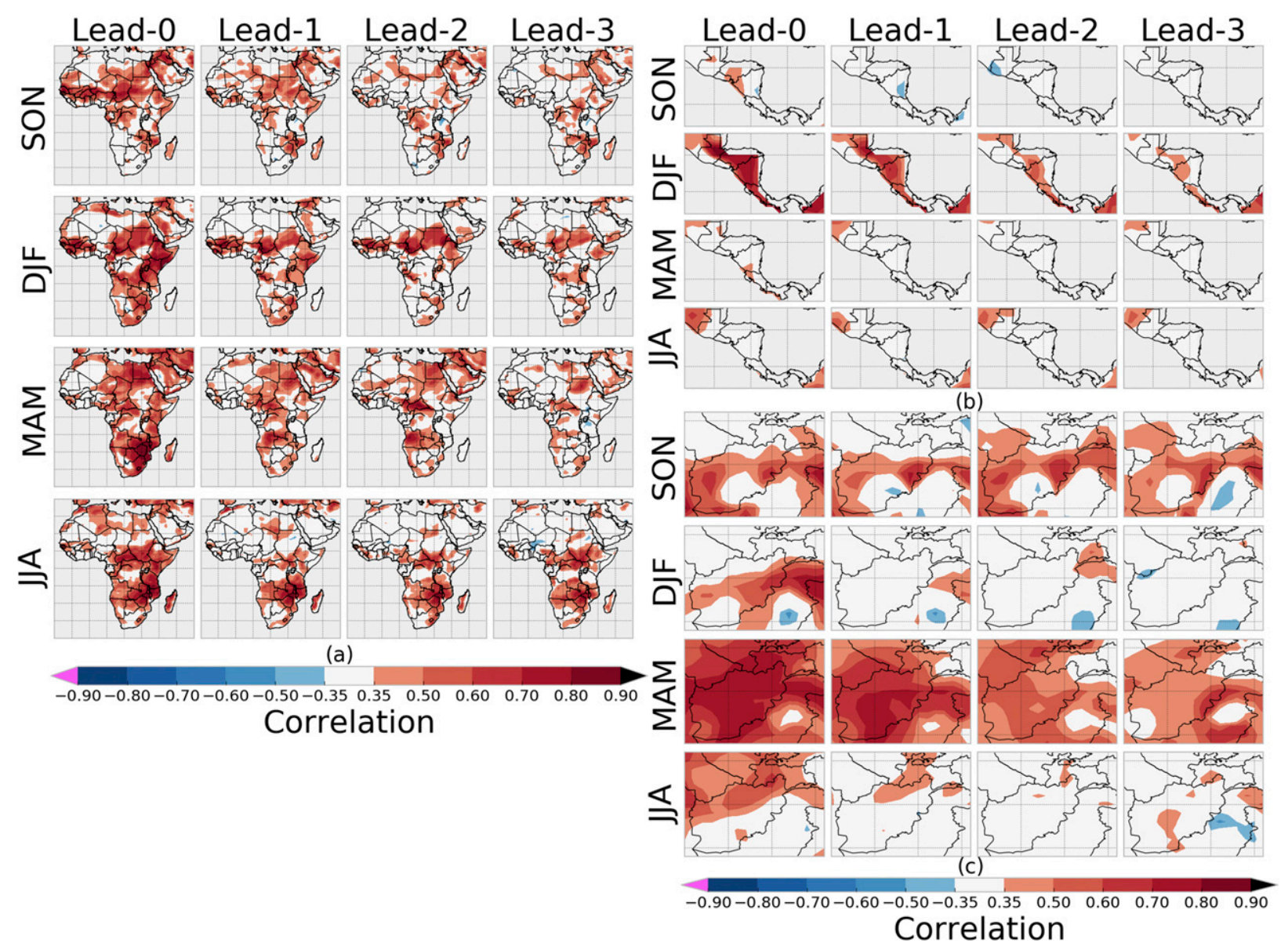

FIG. 2. Deterministic skill (correlation) of 0-3-month-lead multimodel ensemble mean seasonal $\mathrm{ET}_{0}$ forecasts for climatologically wet and dry seasons in FEWS NET focus regions: (a) Africa, (b) Central America, and (c) central Asia.

seasons from lead 0 through lead 3. In general over Africa (Fig. 2a), skill ( $>0.35$ correlation) is apparent over most of the region at lead 0. The skillful region in Africa is smallest for SON. There are only a few regions where in some seasons the skill persists through a lead of 3 months. For Central America (Fig. 2b) the skill is generally only apparent for DJF and up to lead 3 in some parts. For central Asia (Fig. 2c), although the skill is mainly present for MAM, there is also limited skill for central parts of this region for SON. Table 1 lists the regions and seasons in FEWS NET focus regions for which the skill exceeds the 0.35 correlation threshold up to lead 3 .

Figure 3 shows the RPSS for FEWS NET focus regions for all seasons up to leads of 3 months. Overall, RPSS is generally positive for most regions in Africa (Fig. 3a). For central Africa (Fig. 3b) positive RPSS is generally limited to DJF. For central Asia (Fig. 3c) positive RPSS prevails over a large fraction of the region in MAM. In general, the RPSS is $>0.10$ for up to lead 3 over the same regions and seasons for which the correlation values are $>0.35$ for up to a 3-month lead (Table 1).
Figure 4 shows the reliability of lead-0 seasonal $\mathrm{ET}_{0}$ forecasts for each of the tercile categories (the same information for lead 1 is shown in online supplemental Fig. S2). For this analysis, Africa is divided into eastern $\left(5^{\circ} \mathrm{S}-15^{\circ} \mathrm{N}, 33^{\circ}-52^{\circ} \mathrm{E}\right)$, central $\left(5^{\circ} \mathrm{S}-15^{\circ} \mathrm{N}, 10^{\circ}-33^{\circ} \mathrm{E}\right)$, western $\left(5^{\circ} \mathrm{S}-15^{\circ} \mathrm{N}, 18^{\circ} \mathrm{W}-10^{\circ} \mathrm{E}\right)$, and southern Africa $\left(35^{\circ} \mathrm{S}-\right.$ $\left.5^{\circ} \mathrm{N}, 10^{\circ}-50^{\circ} \mathrm{E}\right)$. As indicated in Fig. 4, in general, forecasts for the lower tercile category are more reliable, followed by forecasts for the upper tercile, followed by the normal category. The forecasts are also generally more reliable for regions and seasons of high skill (Table 1) for upper and lower tercile categories.

\section{Example application of $\mathbf{E T}_{\mathbf{0}}$ forecasts}

The analysis thus far has focused on the evaluation of the skill of $\mathrm{ET}_{0}$ forecasts through various skill scores. Longterm skill analyses of forecasts are necessary to inform end users of the seasons and regions for which those forecasts can be most effective. This section presents an example of how $\mathrm{ET}_{0}$ forecasts can complement FEWS NET's existing 


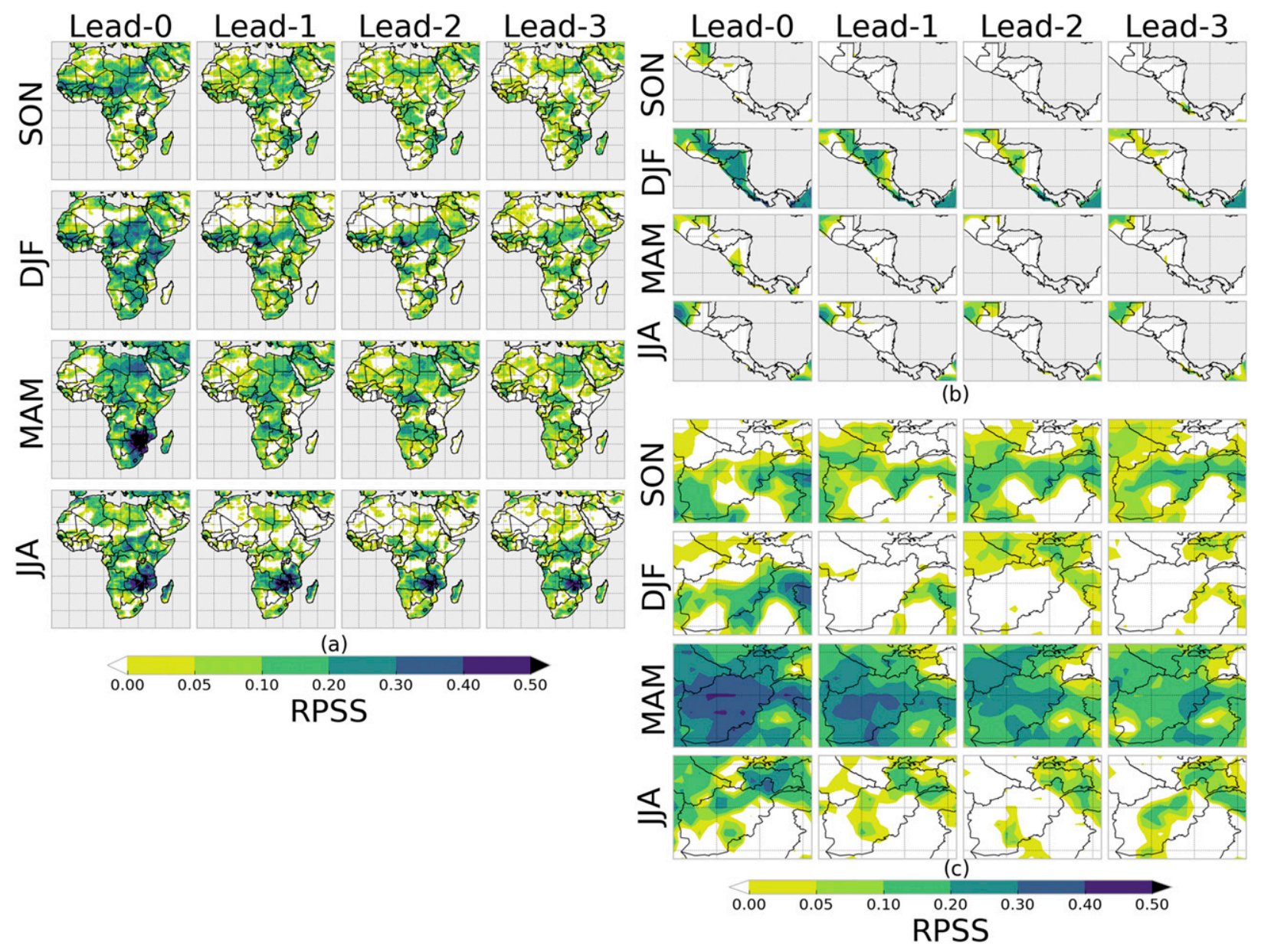

FIG. 3. Probabilistic skill (RPSS) of 0-3-month-lead multimodel seasonal $\mathrm{ET}_{0}$ forecasts for climatologically wet and dry seasons in FEWS NET focus regions: (a) Africa; (b) Central America; and (c) central Asia.

drought-forecasting tools. Here we focus on East Africa (comprising parts of Ethiopia, Sudan, and Uganda) where JJA is an important rainy season. The choice of the region and season in this case is guided by 1) the relatively high and consistent skill of $\mathrm{ET}_{0}$ forecasts (section 3 ) and precipitation forecasts, as reported by Shukla et al. (2017), and 2) the level of food and water insecurity in this region. Some of the most severe drought events since the early 2000s (in 2002, 2004, and 2009) had a common climatic feature: the region experienced both below-normal precipitation and above-normal $\mathrm{ET}_{0}$, with the latter likely exacerbating the impacts of the former. Figures $5 \mathrm{a}$ and $5 \mathrm{~b}$ show the median of the standardized anomaly of $\mathrm{ET}_{0}$ and precipitation forecasts for JJA of those years, with lead 0 being the forecast made in June and lead 3 being the forecast made in March. Seasonal $\mathrm{ET}_{0}$ and precipitation were consistently forecast to be respectively above and below normal, with the severity of the forecast anomalies increasing closer to the season. This example highlights the potential value of $\mathrm{ET}_{0}$ forecasts for food insecurity assessments because they complement the precipitation forecasts and provide a more confident outlook for looming severe drought events, relative to outlooks that are based solely on precipitation forecasts. Timely forecasts of even a tendency toward a severe drought development help to bring the region concerned to the attention of the national, regional, and international agencies. They trigger a more careful and regular monitoring of the agroclimatic conditions that can contribute to a timely and appropriate response to mitigate adverse impacts of the drought events.

\section{Concluding remarks}

This study evaluates the skill of $\mathrm{ET}_{0}$ forecasts globally, with a particular emphasis on FEWS NET regions to examine if they can be of value for FEWS NET's food insecurity outlook assessments. The key findings are as follows:

1) The skill is generally the highest over shorter lead times and shows regional and seasonal variation. 


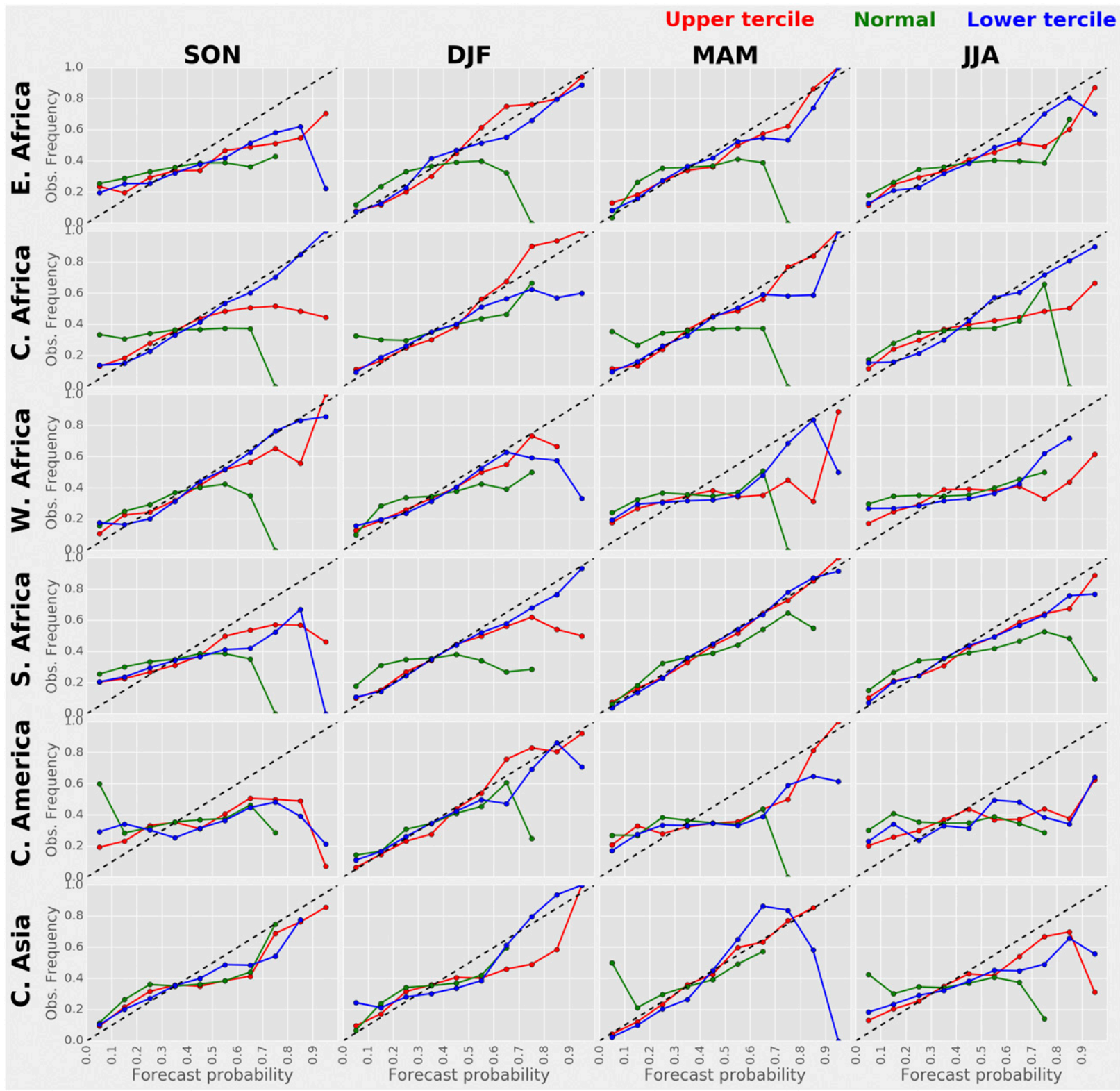

FIG. 4. Reliability of multimodel ensemble lead-0 seasonal $\mathrm{ET}_{0}$ forecasts for all FEWS NET focus regions. The dashed line represents perfect reliability.

The regions where forecasts are most skillful (correlation $>0.35$ at lead 2) include the western United States, northern parts of South America, parts of the Sahel region, and southern Africa.

2) Multimodel skill is generally higher than the skill of an individual model.

3) The FEWS NET season and region combinations for which forecasts are most skillful (correlation $>0.35$; RPSS $>0.1$ ) at least 3 months in advance of the season include DJF for northern sub-Saharan Africa and Central America, JJA for southern Africa and parts of East Africa, and MAM for central Asia.
The above findings have important implications for FEWS NET and other regional drought early warning systems globally, such as the California and Nevada Drought Early Warning System (https:// www.drought.gov/drought/dews/california-nevada) and the Mongolia Livestock Early Warning System (http://www.mongolialews.net/). It is found that $\mathrm{ET}_{0}$ forecasts can be a particularly promising tool for early warning during the dry seasons. When the $\mathrm{ET}_{0}$ skill is high during the rainy seasons, it can be used in combination with precipitation forecasts to more accurately predict the severity of upcoming drought events 


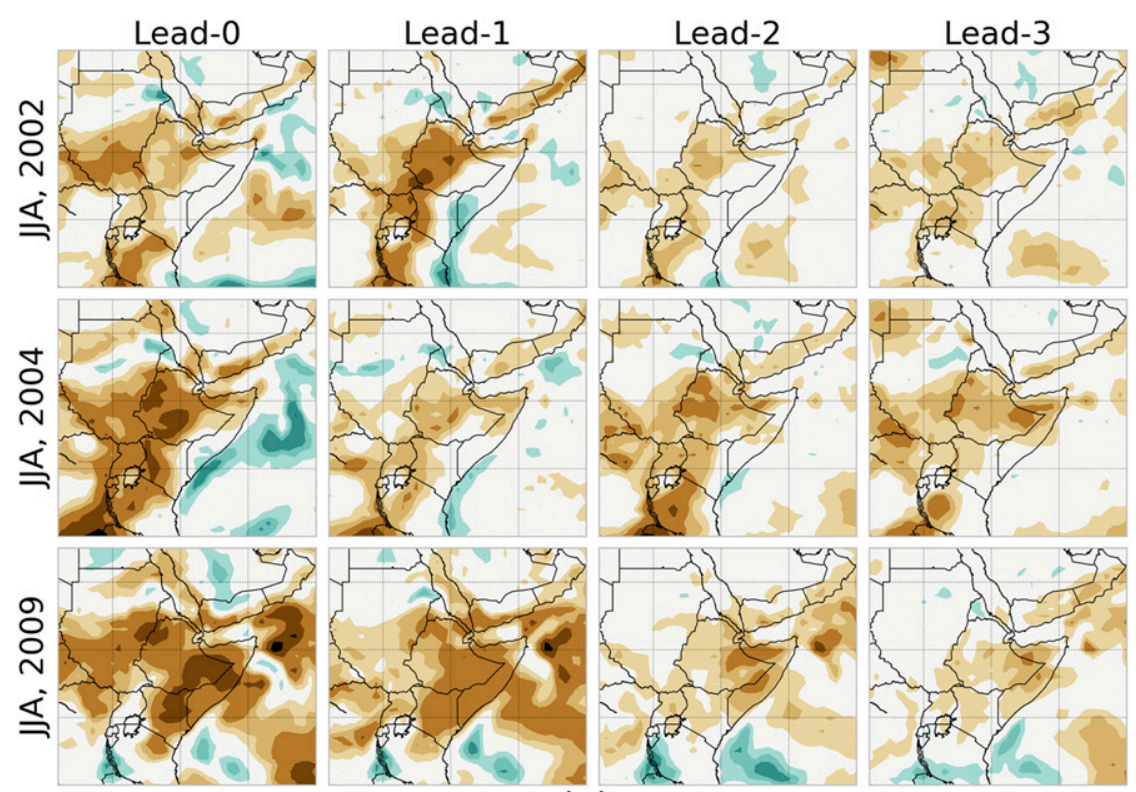

(a)

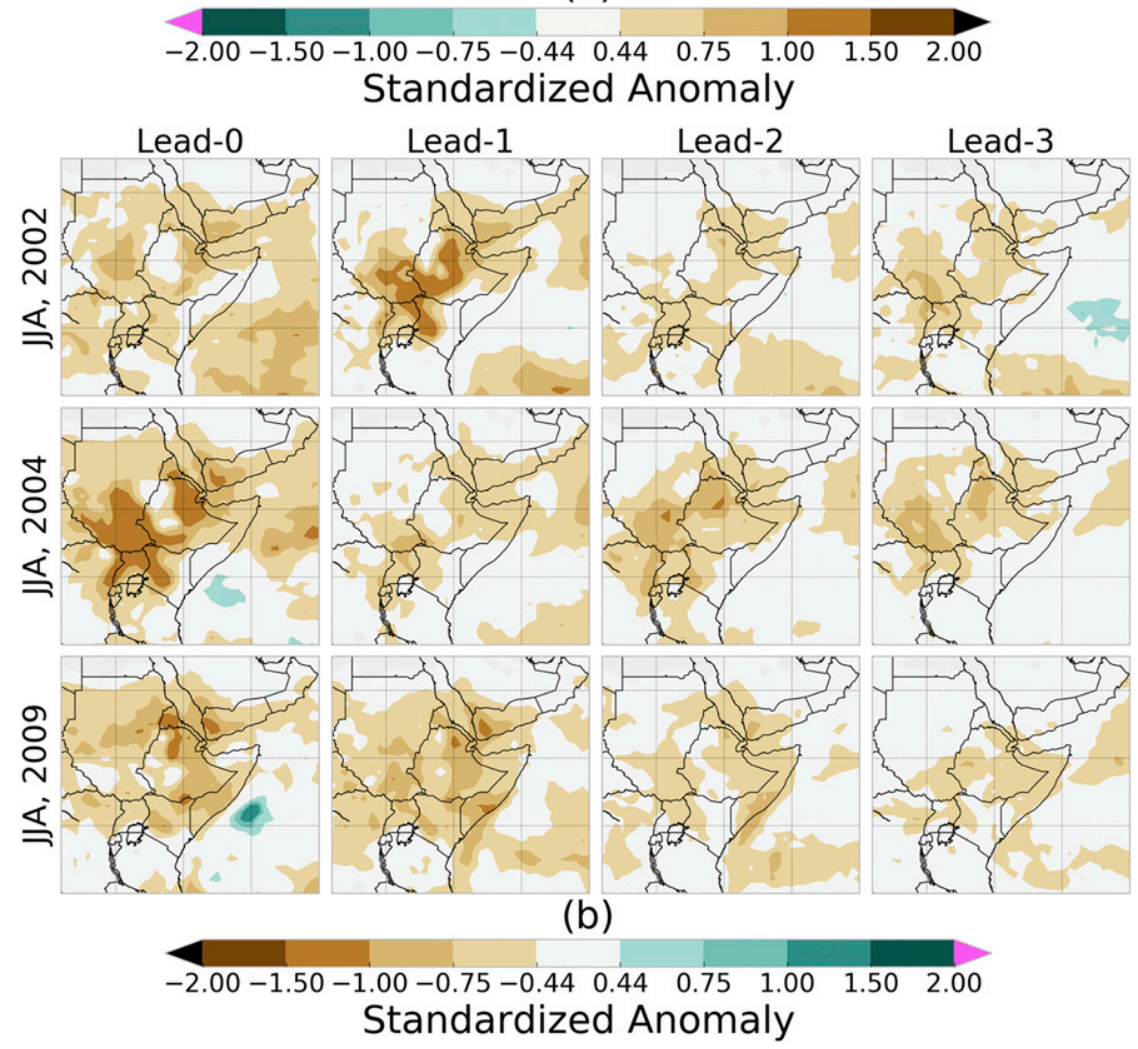

FIG. 5. Median of JJA multimodel ensemble (a) $\mathrm{ET}_{0}$ forecasts (in terms of standardized anomaly) and (b) precipitation forecasts for the drought events of 2002, 2004, and 2009 made from March (lead 3) through June (lead 0) of the respective years.

(section 4). Even in cases with low precipitation forecast skill during the rainy season, skillful $\mathrm{ET}_{0}$ forecasts can help to provide a better estimate of moisture availability. $\mathrm{ET}_{0}$ forecasts can also be used to drive existing FEWS NET tools such as the water requirement satisfaction index (Senay et al. 2011; Verdin and Klaver 2002), which is a crop water balance model designed for predicting crop yield and 
rangeland conditions, or to develop new early warning products such as the standardized precipitation evapotranspiration index (Vicente-Serrano et al. 2010) forecasts. FEWS NET and collaborators have Internet portals on which some of these products can be hosted. Furthermore, FEWS NET supports capacity building in the region through training that ensures that end users (e.g., regional climate agencies and national meteorological agencies) have access to the $\mathrm{ET}_{0}$ forecast-based products and are well equipped to use them to support informed decision-making processes.

Acknowledgments. We thank the NASA GMAO team for making reforecasts of GEOS5 available to us and acknowledge support from NASA SERVIR-AST Grant NNX16AN14G, the U.S. Geological Survey's Cooperative Agreement G09AC000001 and Great Basin Cooperative Ecosystem Study Unit, and the National Oceanic and Atmospheric Administration's National Integrated Drought Information System.

\section{REFERENCES}

Allen, R. G., I. A. Walter, R. Elliott, T. Howell, D. Itenfisu, and M. Jensen, 2005: The ASCE standardized reference evapotranspiration equation. ASCE-EWRI Task Committee Rep. 0-7844-0805-X, 59 pp., http://www.kimberly.uidaho.edu/ water/asceewri/ascestzdetmain2005.pdf.

Brown, M. E., C. C. Funk, G. Galu, and R. Choularton, 2007: Earlier famine warning possible using remote sensing and models. Eos, Trans. Amer. Geophys. Union, 88, 381-382, doi:10.1029/2007EO390001.

Funk, C., and Coauthors, 2015: The climate hazards infrared precipitation with stations-A new environmental record for monitoring extremes. Sci. Data, 2, 150066, doi:10.1038/ sdata.2015.66.

Hobbins, M. T., A. Wood, D. J. McEvoy, J. L. Huntington, C. Morton, M. Anderson, and C. Hain, 2016: The evaporative demand drought index. Part I: Linking drought evolution to variations in evaporative demand. J. Hydrometeor., 17, 1745-1761, doi:10.1175/JHM-D-15-0121.1.

Jenkerson, C. B., T. K. Maiersperger, and G. L. Schmidt, 2010: eMODIS: A user-friendly data source. U.S. Geological Survey Open-File Rep. 2010-1055, 22 pp., https://pubs.usgs.gov/of/ 2010/1055/pdf/OF2010-1055.pdf.

Kirtman, B. P., and Coauthors, 2014: The North American Multimodel Ensemble: Phase-1 seasonal-to-interannual prediction; Phase-2 toward developing intraseasonal prediction. Bull. Amer. Meteor. Soc., 95, 585-601, doi:10.1175/BAMS-D-12-00050.1.
Kumar, S., P. A. Dirmeyer, and J. L. Kinter III, 2014: Usefulness of ensemble forecasts from NCEP Climate Forecast System in sub-seasonal to intra-annual forecasting. Geophys. Res. Lett., 41, 3586-3593, doi:10.1002/2014GL059586.

McEvoy, D. J., J. L. Huntington, M. T. Hobbins, A. Wood, C. Morton, M. Anderson, and C. Hain, 2016a: The evaporative demand drought index. Part II: CONUS-wide assessment against common drought indicators. J. Hydrometeor., 17, 1763-1779, doi:10.1175/JHM-D-15-0122.1.

,,- J. F. Mejia, and M. T. Hobbins, 2016b: Improved seasonal drought forecasts using reference evapotranspiration anomalies. Geophys. Res. Lett., 43, 377-385, doi:10.1002/ 2015GL067009.

McNally, A., and Coauthors, 2017: A land data assimilation system for sub-Saharan Africa food and water security applications. Sci. Data, 4, 170012, doi:10.1038/sdata.2017.12.

Molod, A., L. Takacs, M. Suarez, and J. Bacmeister, 2015: Development of the GEOS-5 atmospheric general circulation model: Evolution from MERRA to MERRA2. Geosci. Model Dev., 8, 1339-1356, doi:10.5194/gmd-8-1339-2015.

Saha, S., and Coauthors, 2014: The NCEP Climate Forecast System version 2. J. Climate, 27, 2185-2208, doi:10.1175/ JCLI-D-12-00823.1.

Senay, G. B., J. P. Verdin, and J. Rowland, 2011: Developing an operational rangeland water requirement satisfaction index. Int. J. Remote Sens., 32, 6047-6053, doi:10.1080/ 01431161.2010 .516028$.

Shukla, S., J. Roberts, A. Hoell, C. C. Funk, F. Robertson, and B. Kirtman, 2017: Assessing North American Multimodel Ensemble (NMME) seasonal forecast skill to assist in the early warning of anomalous hydrometeorological events over East Africa. Climate Dyn., doi:10.1007/s00382-016-3296-z, in press.

Takacs, L. L., A. Molod, and T. Wang, 1994: Documentation of the Goddard Earth Observing System (GEOS) general circulation model, version 1. Technical Report Series on Global Modeling and Data Assimilation, Vol. 1, M. J. Suarez, Ed., NASA Tech. Memo. 104606, Vol. 1, 106 pp, https://ntrs.nasa. gov/archive/nasa/casi.ntrs.nasa.gov/19950005172.pdf.

Velpuri, N. M., G. B. Senay, J. Rowland, J. P. Verdin, and H. Alemu, 2014: Africa-wide monitoring of small surface water bodies using multisource satellite data: A monitoring system for FEWS NET. Nile River Basin: Ecohydrological Challenges, Climate Change and Hydropolitics, A. M. Melesse, W. Abtew, and S. G. Setegn, Eds., Springer, 69-95, doi:10.1007/978-3-319-02720-3_5.

Verdin, J., and R. Klaver, 2002: Grid-cell-based crop water accounting for the famine early warning system. Hydrol. Processes, 16, 1617-1630, doi:10.1002/hyp.1025.

Vicente-Serrano, S. M., S. Beguería, and J. I. López-Moreno, 2010: A multiscalar drought index sensitive to global warming: The standardized precipitation evapotranspiration index. J. Climate, 23, 1696-1718, doi:10.1175/2009JCLI2909.1. 